\title{
GERAÇÃO BOLSA FAMÍLIA \\ Escolarização, trabalho infantil e consumo \\ na casa sertaneja (Catingueira/PB)*
}

\section{Flávia Ferreira Pires \\ George Ardilles da Silva Jardim}

\section{Introdução}

Esse artigo faz parte dos esforços de compreensão dos efeitos do Programa Bolsa Família (PBF) na cidade de Catingueira, Paraíba, quanto às dinâmicas familiares e ao papel que as crianças passam a desempenhar em consequência do recebimento do benefício. ${ }^{1}$ Nosso objetivo é tecer considerações a respeito de mudanças geracionais que vêm sendo engendradas a partir desse programa, em função do recebimento

* Agradecemos ao apoio financeiro recebido do CNPq através do projeto de pesquisa "A Casa Sertaneja e o Programa Bolsa Família" (2009-2011); ao trabalho da equipe de pesquisadores, composta por Patrícia Oliveira Santana dos Santos, Tatiana Benjamin e Jéssica Karoline Rodrigues e, sobretudo, à generosa recepção que tivemos entre os catingueirenses.

Artigo recebido em 17/01/2014

Aprovado em 25/03/2014 de uma renda regular. Essas mudanças estão relacionados com a expansão do consumo, a escolarização das crianças e o trabalho infantil. Pretendemos, portanto, compreender tais mudanças sugerindo o conceito de "geração bolsa família" (Pires, 2010b).

Entendemos geração como um conjunto de indivíduos que compartilham um momento histórico determinado, marcado pelo nascimento, e que, como consequência, estão sujeitos aos mesmos processos históricos-sociais. Em confronto com a definição de Meyer Fortes, para quem as gerações "calcadas genealogicamente, [...] se geram unicamente no núcleo familiar de pais e filhos" (Domingues, 2002, p. 73), Debert salienta experiências que ultrapassam o núcleo familiar: "mais do que a idade cronológica, [geração] é a forma privilegiada de os atores darem conta de suas experiências extrafamiliares" (Debert, 1994, p. 19). Aqui daremos destaque às experiências de vida dos membros de uma família. Acreditamos, como Corsten, "que 
as geraçóes somente se constroem em processos de interação com outras gerações, ao delas se "distinguirem": o discurso de "gerações que co-existem" é "co-construtivo" (Domingues, 2002, p. 71). É nesse contexto que entendemos a mudança geracional, que se dá a partir de um processo reflexivo em que os sujeitos vêem, baseados em suas experiências biográficas, transformaçōes histórico-sociais significativas em relação aos indivíduos de classes etárias que os sucederam dentro de uma mesma família.

A principal pesquisa de campo que originou este texto foi realizada em dezembro de 2010, com a participação de cinco pesquisadores. Foram feitas 22 entrevistas semiabertas com os responsáveis pelo recebimento do benefício, na grande maioria das vezes, as mães. Majoritariamente em duplas, os pesquisadores seguiram um roteiro de perguntas que focava vários aspectos do PBF e durava, em média, 2 horas. Tendo sido constatado pela equipe de pesquisadores, através de conversas com os moradores, um evidente impacto do programa na vida das pessoas, uma das perguntas dizia respeito ao "antes e depois do PBF". O que mudou na vida da família com a chegada do PBF? - foi uma das perguntas feitas às mães. Em larga medida, é sobre os dados obtidos a partir dessa pergunta que o presente artigo se justifica. Mas, além das entrevistas, realizamos também observação participante durante os sete dias de estadia na cidade de Catingueira. Ficamos "hospedados" em casas de beneficiários do programa, onde fazíamos as refeições, dormíamos, tomávamos banho; enfim, pudemos vivenciar, ainda que por pouco tempo, o cotidiano familiar. Vale lembrar, ademais, que realizamos pesquisas de campo no mesmo município há mais de uma década, utilizando técnicas de pesquisa variadas, o que também ajudou a elaboração deste artigo. ${ }^{2}$ Inspirados pela "maison kabyle" (Bourdieu, [1970] 1999), usamos a ideia de "casa sertaneja" no seu sentido estritamente etnográfico, isto é, a família ou o fogo-familiar na região pesquisada - "sertaneja" é como essa população se define; "casa" é uma metáfora para o conceito mais abstrato de família, que inclui a moradia, mas a ultrapassa.

A pequena cidade de Catingueira - localizada no semiárido nordestino, no estado da Paraíba, tem fortes raízes camponesas e conta com uma popula- ção de 4.812 habitantes, segundo o Censo 2010, distribuídos entre as zonas rural e urbana. Mesmo morando na cidade, muitos mantêm uma roça, onde plantam principalmente feijão e milho. Crianças e jovens podem estudar na cidade até completarem o ensino médio, mas para cursar a universidade precisam migrar ou realizar deslocamentos diários para outras cidades. As mulheres são normalmente donas de casa e cuidam dos filhos, enquanto os homens realizam trabalhos, temporários ou não, fora da cidade. Moças e rapazes, quando têm sorte ou ligações de parentesco, são empregados nos pequenos comércios da cidade. A aspiração financeira de grande parte da população é um emprego na prefeitura, tendo em vista a estabilidade e a remuneração. Do ponto de vista da economia local, as famílias sobrevivem da agricultura de subsistência, de pequenos comércios, empregos públicos na prefeitura e benefícios governamentais, como o PBF e as aposentadorias. Segundo os dados do Ministério do Desenvolvimento Social e Combate à Fome (MDS), do total de 1.207 famílias cadastradas, 1.162 contam com renda per capita mensal de até $1 / 2$ salário mínimo, o que caracteriza a população como extremamente pobre. O IDHM de Catingueira é 0,56, segundo a PNUD 2000. Um contingente populacional estimado de 2.992 pessoas, ou seja, $62 \%$ da população ${ }^{3}$ é beneficiário do programa. Essa larga proporção aliada à baixa monetização da região tornam essa cidade privilegiada para se observar os efeitos do PBF, ao contrário de cidades de médio e grande porte, aspecto que foi ressaltado pelo Relatório Executivo do Cedeplar (2007).

Embora na cidade pesquisada o PBF seja considerado um marco histórico - os moradores vislumbram um "antes" e um "depois" da sua implementação -, é importante situar os dados aqui apresentados no processo histórico-social brasileiro em relação aos programas que o precederam e a programas similares implantados em outros países. Essa análise situacional será realizada parcialmente, já que daremos destaque às dimensões do programa que afetam as políticas do cotidiano, como práticas de consumo e sutis mudanças nas formas de relação intrafamiliares entre adultos e crianças.

Este artigo está dividido em três partes, além das sessões introdutória e conclusiva. A primeira 
parte trata de apresentar suscintamente o PBF, ressaltando as condicionalidades. $\mathrm{Na}$ segunda parte, trazemos informações sobre a expansão do consumo propiciada pelo programa no munícipio pesquisado, como um primeiro indício das mudanças geracionais em andamento. Dando prosseguimento, na terceira parte, empreenderemos uma reflexão sobre a escolarização e o trabalho infantis, trazendo à baila o conceito "geração bolsa família" (Pires, 2010b) como forma de compreender as mudanças geracionais engendradas pelo PBF.

\section{O Programa Bolsa Família}

Apresentaremos o PBF de maneira suscita, atentando para um aspecto crucial do programa de acordo com os nossos interlocutores: as condicionalidades.

O PBF foi criado pelo governo federal em outubro de 2003, através da unificação de quatro benefícios anteriores (Bolsa Escola, Auxílio Gás, Bolsa Alimentação, Cartão Alimentação), buscando melhor atender os usuários, aumentando os valores monetários transferidos, melhorando a gestão e ampliando a efetividade do gasto social (Silva, 2007; Monnerat et al., 2007). O PBF concentra-se em três dimensões essenciais para o enfrentamento da fome e da pobreza: 1) o alívio imediato da pobreza, por meio de transferências diretas de renda; 2) o apoio ao desenvolvimento das capacidadas das famílias por meio de programas complementares, como o Peti (Programa de Erradicação do Trabalho Infantil); e 3) o reforço ao exercício de direitos sociais básicos como saúde e educação, através das condicionalidades. O benefício é destinado a dois tipos de famílias: pobres e extremamente pobres, com base na sua renda mensal per capita. As primeiras com renda mensal per capita de até $\mathrm{R} \$ 70,00$ e as segundas, de até $\mathrm{R} \$ 140,00$. O valor do benefício é calculado caso a caso, levando em conta o número de crianças, adolescentes, mulheres nutrizes ou grávidas na residência, variando entre $\mathrm{R} \$ 32,00$ e $\mathrm{R} \$ 306,00$.

O PBF também pode ser visto como um primeiro passo para a instituição de uma renda universal, que no Brasil tomou a forma da lei n. 10.835/2004, aprovada no Congresso Federal em
2003 (sancionada pelo presidente Lula em 2004). A Renda Básica de Cidadania foi proposta pelo senador Eduardo Suplicy e estabelece a implantação gradativa de uma renda universal (não condicionada) a todos os cidadãos que moram no Brasil (Suplicy, 2006). Cogita-se se tal projeto teria o apoio da opinião pública brasileira, tendo em vista a voracidade com que a mídia tratou o fato de que o governo brasileiro, nos primeiros anos de implantação do $\mathrm{PBF}$, não controlava o cumprimento das condicionalidades, acusando-o de paternalista (De Britto, 2008; Hanlon et al., 2010). Esse fato levou alguns pesquisadores a afirmarem que as condicionalidades brasileiras eram "suaves" (Hanlon et al., 2010 , p. 40), ou seja, não resultavam em corte ou suspensão do benefício, mas estavam em sintonia com uma renda de cidadania, reforçando os direitos universais básicos.

No entanto, o programa é um benefício de transferência de renda condicionada e, hoje em dia, as condicionalidades são verificadas bimensalmente para a área da educação e, bianualmente, para a área da saúde ${ }^{4}$ (MDS, 2011; Fiszbein e Schady, 2009). As condicionalidades são consideradas necessárias para alcançar o objetivo último do PBF, qual seja, o rompimento do ciclo geracional da pobreza, que condena famílias pobres à inércia na ascensão social por geraçōes. Para garantir seu benefício mensal, espera-se que as famílias passem a fazer uso dos serviços de educação e saúde. Com isso, almeja-se a quebra do ciclo da pobreza, entendido em sua dimensão histórica, econômica, cultural e política (Silva, 2007).

As condicionalidades engendram vários debates. Questiona-se, por exemplo, a validade do PBF como uma política de cidadania. Segundo Zimmerman (2006), o PBF não se baseia numa concepção de direitos justamente por impor contrapartidas para o provimento dos benefícios. Educação e saúde são direitos básicos do cidadão brasileiro garantidos pela Constituição, antes de serem obrigatoriedades do programa. Muitos autores, a exemplo de Lavinas (2006), Zimmerman (2006) e o próprio Suplicy (2006, 2007), questionam a legitimidade dessas contrapartidas. Silva sinteza um argumento comum entre esses autores: "[as] condicionalidades deveriam ser impostas ao Estado [...] e não às famílias” (2007, 
p. 1436), já que os municípios são responsáveis pela disponibilização dos serviços de saúde e educação para a população. Os agentes nacionais dos programas de transferência condicionada de renda (não apenas no Brasil) e também atores internacionais, como o Banco Mundial, têm insistido na ideia da "corresponsabilidade". De um lado, o Estado tem por obrigação prover os serviços básicos, com qualidade e boa cobertura; de outro, as famílias têm o dever de acessá-los. Com a ênfase na corresponsabilidade espera-se retirar o teor negativo de punição, normalmente associado às condicionalidades.

Podemos supor que as condicionalidades do PBF seriam um meio de estimular o exercício da cidadania, através de uma política social que tem como regra a utilização dos serviços sociais básicos por parte de uma população que, do contrário, não os acessaria. As condicionalidades apenas se justificam quando partimos do pressuposto de que os investimentos em capital humano feitos pelos pobres não são suficientes, que os mesmos não priorizam a escolarização e a saúde dos filhos; havendo, portanto, a necessidade de incentivar uma mudança comportamental através de ajuda do incentivo financeiro (Fiszbein e Shady, 2009, p. 66; De Britto, 2008, p. 189). Contudo, a ideia de que os pobres não acessam os serviços básicos por falta de motivação pessoal não pode ser tomada como um dado a priori. Ela mascara a falência do sistema público de saúde e educação, muitas vezes inexistentes ou promovendo serviços inaquedados, razões legítimas para o não acesso ou o acesso limitado por parte das famílias pobres. Isso nos permite concordar com Bradshaw e Víquez quando afirmam que "[...] não é o 'mal' comportamento do pobre que precisa ser mudado, mas sua capacidade para se comportar bem que precisa ser reforçada" (2008, p. 837). O que pode estar acontecendo, em muitos casos, é a precariedade da disponibilização desses serviços por parte da administração pública. As pessoas estão dispostas a fazer uso dos serviços se eles estiverem disponíveis com uma qualidade mínima de atendimento. Em Catingueira, a qualidade do serviço de saúde e educação é considerada ruim, embora isso não configure, para a população, motivo suficiente para o não comparecimento à escola ou ao posto de saúde, ao contrário do que foi observado por Ada- to (2008) em relação ao Programa de Mitigação de Risco Social na Turquia.

Alguns autores questionam a eficácia das condicionalidades na garantia do acesso ao sistema público, já que, mesmo quando não condicionado, o aumento na renda familiar leva a um maior investimento em educação e saúde (Hanlon et al., 2010, pp. 55,72; Bradshaw e Víquez, 2008, p. 827). Nesse sentido, não seriam as condicionalidades, mas o dinheiro que faz a diferença (Lund et al, 2009; Bradshaw e Víquez, 2008, p. 827). Seria possível, então, atingir os mesmos níveis de frequência escolar e acompanhamento médico dispensando as condicionalidades (De Britto, 2008, p. 189)?

Em Catingueira, atualmente o incentivo ao estudo está presente no discurso familiar, como analisaremos com mais detalhes adiante. Mas não temos evidências para supor que isso seja uma mudança engendrada pelo PBF, pois nas geraçōes anteriores também existia o interesse pela escola. Não havia, no entanto, meios de acessar esse sonho, por falta de recursos materiais e pela dificuldade de acesso à escola. A democratização do ensino público permitiu maior facilidade de acesso à escola, e, ao mesmo tempo, a transferência monetária garantiu que a criança não precisasse trabalhar para completar a renda da casa e pudesse continuar seus estudos. Como o desejo de estudar foi largamente observado na geração das mães, acreditamos que seja o dinheiro e não necessariamente a condicionalidade que garanta a frequência escolar. Em outras palavras, o que mantém as crianças na escola é o acréscimo da renda familiar e não a obrigatoriedade da escolarização. Nesse sentido, é importante que se avalie a possibilidade de tornar o benefício financeiro incondicional e universal (Lavinas, 2006; Suplicy, 2006).

\section{Expansão do consumo: criança como prioridade}

O PBF alterou a dinâmica financeira das famílias, propiciando, para uma larga parcela da população brasileira, a primeira experiência de recebimento de renda regular e, por conseguinte, a entrada no mercado de consumo. ${ }^{5}$ Rego (2008) e Rego e Pinzani (2013) analisam as consequencias 
políticas do recebimento do dinheiro. Assim como os autores, acreditamos que o acesso ao dinheiro é importante para se atingir emancipação política. Em direção complementar à sua pesquisa, perguntamo-nos: como as famílias empregam o dinheiro recebido? É sobre isso que trataremos neste tópico, atentando para as mudanças em relação às gerações anteriores no que diz respeito ao consumo e à priorização das crianças em relação ao gasto do benefício. A pergunta de fundo que nos propomos a responder aqui é se uma renda regular contribui para o processo de mudança geracional no que concerne ao consumo e às relações intrafamiliares.

O programa também faz das mulheres as legítimas beneficiárias. Embora não nos detenhamos neste aspecto aqui, isso é importante para compreender o PBF e suas consequências para as mudanças geracionais vislumbradas. Acredita-se que as mulheres, em relação aos homens, otimizam os gastos domésticos de maneira mais eficiente, previlegiam os mais vulneráveis quando os recursos são escassos e investem mais na saúde e na educação das crianças. Nesse sentido, elas são consideradas "instrumentos" para o alcance dos objetivos do programa, notadamente, o bem-estar das crianças (Lomeli, 2008, p. 489). Todavia, este foco nas mulheres pode ocasionar um efeito double-bind (Cf. Bateson, 2000; Pires, 2014). De um lado, elas ganham autonomia, pois não dependem mais do marido para as compras cotidianas (Suárez et al., 2006; Rego, 2008; Adato, 2008); de outro, deixam-nas mais presas ao universo doméstico. Alguns autores argumentam que os programas de transferência condicionada de renda, a exemplo do PBF brasileiro e do Oportunidades mexicano, tem re-tradicionalizado os papéis de gênero e das funções associadas à maternidade (Molyneux, 2006; Quijano, 2009). Mas, no momento, interessa-nos enfatizar que é a mulher, na grande maioria dos casos observados, quem gere o recurso recebido.

O fato de o gasto do benefício não ser tutelado pelo governo é exaltado pelos pesquisadores (Hall, 2006, p. 692; De Britto, 2008, p. 189; Suplicy, 2006; Hanlon et al., 2010; Lavinas e Barbosa, 2000) que reconhecem nesse traço do programa um passo necessário (embora não suficiente) para o florecimento de uma política cidadã. Hanlon et al. (2010) enfatizam o fato de que os pobres fazem boas escolhas com o dinheiro das transferências de renda, usando seus parcos recursos em atividades que promovem a geração de renda, como a compra de itens para revenda; compra de instrumentos agrícolas que propiciam um melhor aproveitamento do tempo dedicado à agricultura e investimentos em pequenos negócios. Estas dinâmicas foram observadas em Catingueira: abertura de pequenos comércios; crescimento de vendas de porta em porta; compras de motocicletas que ajudam no transporte rural. Isso nos leva tanto a discordar de Hall (2006) quando enfatiza a crescente dependência dos pobres em relação aos benefícios do governo, como de Farrington e Slater (2006, p. 500), que acreditam que o dinheiro do PBF é todo gasto em consumo imediato, o que não propicia a criação de renda.

Quanto ao uso do dinheiro recebido, os gastos com alimentação são prioridade. Todavia, foi muito comum nas falas das entrevistadas a referência ao pagamento das contas de fornecimento de água e de energia elétrica. Muitas donas de casa já levam os "papéis" (contas) de água e de luz no momento em que vão à lotérica retirar o benefício. ${ }^{6} \mathrm{O}$ aluguel também é uma prioridade para quem não tem casa própria. Outro gasto mencionado foi com remédios, como nos contou dona Benedita ${ }^{7}-$ o benefício que ela recebe complementa a renda familiar e é destinado primeiramente à compra de remédios do coração, não disponíveis na farmácia do governo. Em seu livro sobre o PBF, cuja análise se baseia nas cartas escritas ao presidente Lula, Cohn (2012) enfatiza que o beneficio é muitas vezes utilizado para suprir necessidades familiares prementes, como despesas de saúde. Segundo ela, o programa acaba sendo um "complemento do SUS". Em resenha deste livro, Escorel afirma: "O BF absorve as insuficiências e preenche as lacunas das demais políticas setoriais: substitui a previdência social, tanto a aposentadoria quanto o auxílio doença; é a 'bolsa permanência' na escola, a 'bolsa farmácia' e o 'seguro saúde"” (2014, p. 652). Isso revela a precariedade ou a impossibilidade de acesso a direitos, como saúde e habitação.

Quando não há outra fonte de renda senão o benefício, ele é gasto na compra dos gêneros alimentares básicos. Quando o dinheiro é um com- 
plemento à renda familiar, ele é usado na compra de gêneros alimentares secundários, utensílios domésticos e calçados, vestuário e material escolar para as crianças. Assim acontece com dona Benedita que, com o dinheiro que sobra, depois de quitadas as despesas de saúde, compra algumas coisinhas a mais, como mortadela, pão, queijo, biscoito etc. Os alimentos considerados básicos - feijão, farinha e arroz - vêm do dinheiro que recebe do roçado. No caso de dona Gertrudes, embora não tenha renda do roçado, ela recebe um salário mínimo do INSS em nome de um dos filhos, aposentado por invalidez, o que garante os gastos com a mercearia e o frigorífico. Ela calcula os valores a serem gastos com o grosso da casa a partir desta renda, e com o benefício do PBF salda contas aleatórias e esporádicas do cotidiano, como padaria, lanche e material escolar para os meninos, utensílios para a casa.

Durante nosso trabalho de campo, percebemos constantemente nas salas das residências que visitamos a presença de aparelhos de TV, DVD e som. Observamos também inúmeros DVDs (piratas) de música sertaneja e forró, além de aparelhos e jogos de video game, geladeira e móveis novos. Segundo alguns entrevistados, esses itens eram comprados, em parte, com a renda do PBF. Conversando com a coordenadora do programa em Catingueira, ela afirmou que tinha conhecimento disso, mas não incentivava tal conduta, já que não se tratava de produtos de primeira necessidade. Mas, de maneira geral, ela considerava o resultado positivo, pois no município havia gente que "não tinha absolutamente nada" e pôde, a partir do benefício, garantir a alimentação e adquirir algum tipo de bem durável. Vale lembrar que bens como eletrodomésticos podem ser facilmente convertidos em dinheiro vivo, caso seja necessário acesso rápido à liquidez. Por isso, esses bens muitas vezes podem ser vistos como uma forma de poupança otimizada, o que nos leva a concordar com Hanlon et al. (2010) sobre a boa gestão dos recursos financeiros realizada pelos pobres. Morton (2013) também ressalta o papel desses bens duráveis para a autonomia das mulheres, ao enfatizar seu aspecto de "permanência", em comparação aos bens rapidamente consumidos, como alimentos.

Os efeitos do PBF na cidade de Catingueira estão relacionados com os gastos alimentares prin- cipalmente das crianças. Dona Sebastiana nos contou que o dinheiro do PBF garante sustento e uma boa alimentação para sua filha que, como as outras crianças, gosta de chocolate, iogurte e salgadinho, mas também come comida de verdade. De fato, como vimos em outras entrevistas, a despesa com a alimentação das crianças cobre tanto alimentos básicos, quanto secundários. Chamou-nos a atenção o gasto com leite em pó, principalmente, dos mais caros (Nan e Ninho), o que mostra o consumo altamente seletivo realizado por famílias extremamente pobres. Qualquer leite não serve, tem que ser leite em pó e da Nestlé. Isso revela absolutamente o lugar que as crianças ocupam na vida familiar no que diz respeito aos gastos realizados com o dinheiro da transferência de renda. ${ }^{8}$

Efetivamente. as famílias participantes do programa aumentaram seus gastos com alimentos infantis, o que confirma pesquisa realizada pelo Centro Internacional da Pobreza, o que deveria ser entendido como um efeito positivo sobre a situação nutricional das famílias. "Todavia, a conexão não é direta, pois a melhoria da situação nutricional de crianças e de adultos não depende apenas do nível de gasto com alimentos, mas principalmente da qualidade da dieta" (Soares et al., 2007, p. 9). Segundo Lignani et al. (2011, p. 789), o consumo de alimentos que mais cresceu com o PBF foi o de cereais (principalmente, arroz, mas também farinhas, pão, bolo, macarrão etc.) com um aumento de $73,8 \%$; seguido das comidas processadas (enlatados, salsicha, bebidas alcoólicas, comida pronta, como macarrão instantâneo etc.) com um aumento de $57,1 \%$. Os autores alertam que o maior poder de compra das famílias pobres leva a escolhas de consumo alimentares pouco saudáveis (Idem, p. 785). Em Catingueira, foram observados recentemente os primeiros casos de obesidade infantil, o que enfatiza a necessidade de ações de educação nutricional. Trata-se de uma tarefa desafiadora numa região em que satisfazer os desejos alimentares dos filhos é parte do que se considera o dever de uma boa mãe (Pires, 2013). Dona Rute, por exemplo, comenta que "a menina [sua neta] só quer comer Danone, Todinho e chocolate. E a mãe sempre que pode dar, não nega nada”. A menina, segundo ela, está com o peso acima do recomendado para a sua 
idade. Pensando em segurança alimentar, - além da dificuldade colocada para a função materna no provimento dos desejos e necessidades nutricionais das crianças, que muitas vezes priorizam alimentos de baixo teor nutritivo e alta porcentagem de açúcares e gorduras -; na região sertaneja excessso de peso é geralmente visto como sinônimo de beleza, indicando uma criança bem cuidada e alimentada (Pires, 2010b, 2013).

Adato et al. (2011, p. 1926) alertam para o fato de que as práticas culturais de uma população não podem ser desconsideradas quando se pensa em políticas públicas, sob o risco de serem ineficientes. $\mathrm{O}$ insucesso da papilla, bebida multivitamínica distribuída pelo programa Progresa (hoje Oportunidades) no México como suplemento alimentar para crianças pequenas, mulheres grávidas e lactantes, ilustrativo nesse sentido. Segundo os autores, a bebida não foi consumida segundo as recomendações do programa, mas conforme as regras de socialibilidade doméstica, cujo princípio básico é o compartilhamento de alimentos. De forma que a bebida era sempre consumida coletivamente, dividida entre todos os membros familiares, inclusive visitantes e até mesmo para os médicos em suas visitas domiciliares. No Brasil também é preciso levar em conta o entendimento cultural do excesso de peso como positivo e da função materna de alimentar e atender aos desejos infantis como definidores de uma maternidade bem-sucedida. ${ }^{9}$

Embora o benefício financeiro seja pensado para o usufruto da família como um todo, notamos a prioridade que se dá às crianças, especialmente em gastos alimentares. Isso ocorre por ao menos duas razōes. A primeira diz respeito ao fato de o PBF ser uma continuidade do programa Bolsa Escola. A segunda concerne ao entendimento das famílias beneficiárias de que o PBF é garantido pelo esforço cotidiano das crianças ao cumprem a condicionalidade educacional. Ao frequentar a escola, as crianças garantem a renda e, por isso, devem ser recompensadas. ${ }^{10}$

Por conta disso, as crianças, sem exceção, recebem diretamente parte do benefício. Isso se deve principalmente ao entendimento local de que é a frequência escolar que garante a continuidade do benefício. Deve-se destacar, pois, não só o rigor da verificação da condicionalidade escolar ante as con- dicionalidades da saúde, mas também a memória da população quanto à precedência do programa Bolsa Escola. ${ }^{11}$ As crianças utilizam o dinheiro para comprar alimentos na escola ou na rua; as jovens gastam também com produtos de beleza, roupa íntima, bijuterias - "coisas de mulher", como dizem as mães; os rapazes gastam o dinheiro prioritamente com alimentos comprados na rua, como o pastel da praça, indicando estratégias de sociabilidade juvenil (Pires, 2010b). Também se poupa para compras de itens mais caros (peça de vestuário, sapato, celular, bicicleta) ou para gastar em atividade lúdicas, como o parque de diversōes que visita a cidade na época de festa do padroeiro. ${ }^{12}$ Há, todavia, certa discrepância entre as declaraçôes das mães e o que pudemos observar em termos de consumo entre crianças e adolescentes. Para as primeiras, o gasto é, essencialmente, alimentar, já que na sua visão se trata de uma prioridade. Mas há consumo de bebida alcoólica supostamente patrocinada pelo PBF, além de consumo na área de lazer, como jogos eletrônicos em lan house ou horas nos chats e sítios de relacionamentos, o que raramente é apontado pelas mães.

O direcionamento dos rendimentos financeiros vindos do repasse do PBF para crianças e adolescentes deve-se, pontanto, ao fato de que as famílias enxergam no programa tal prioridade, o que também está refletido nas pesquisas quantitativas (Cecchini e Madariaga, 2011, p. 136; Soares et al., 2007). Além disso, seja complemento ou único rendimento fixo das famílias, o repasse é gasto prioritamente por adultos e crianças em alimentação. Segundo Duarte et al. (2009), as famílias usaram $88 \%$ das transferências em alimentos, Resende e Oliveira (2008) também encontraram resultados similares. Em se tratando do gasto alimentar realizado pelas mães, observamos uma priorização das crianças, tanto pelo repasse direto de renda quanto na compra de itens especialmente para elas, como leite em pó. Em paralelo, seguem os gastos com calçado e vestuário infantis e com material escolar. Chama a atenção de qualquer pessoa que conheceu a cidade há uma década atrás a disponibilidade de produtos considerados naquela data inacessíveis, não só porque indisponíveis para a compra local, mas também pelo preço dos produtos. No entanto, hoje, há uma demanda crescente nesse sentido, o 
que revela a novidade que o recebimento de renda regular representa para essa população.

Embora a alimentação seja prioritária, constatamos uma série de outros gastos, considerados dignos ou indignos, que indicam a diversidade de estratégias e a otimização dos recursos realizados pelas famílias beneficiárias, ${ }^{13}$ mas é inquestionável a priorização do consumo voltado para as crianças, além do repasse direto em espécie à própria criança que frequenta a escola regularmente.

\section{A casa sertaneja entre gerações}

Uma das questôes centrais que o PBF busca combater é a transmissão geracional da pobreza. Sua meta, entre outras, é permitir que as crianças se escolarizem e que não seja necessário recorrer ao trabalho infantil para complementação da renda familiar. Trabalho e escolarização são, nesse sentido, dimensões essenciais. Acreditamos que hoje já é possível indicar alguma mudança geracional, embora sutil, em relação à escolarização das crianças e ao trabalho infantil por parte das famílias catingueirenses. É sobre isso que vamos nos deter neste tópico. ${ }^{14}$

Vida muito sofrida ou muito difícil são expressões que perpassam o discurso das entrevistadas sobre sua infância e a de seus pais. As gerações anteriores ao $\mathrm{PBF}$, segundo elas, tinham necessidade de trabalhar no campo desde cedo para ajudar a família no sustento da casa. Todos elencaram o trabalho como uma das dimensóes mais importantes da sua vida quando crianças. Adulto ou infantil, o trabalho garantia o alimento da casa e a sobrevivência da família. No entanto, além de uma necessidade material, o trabalho infantil em Catingueira está intrinsecamente ligado à educação moral, à socialização e à preparação das crianças para o futuro, ou seja, há aí, certamente, uma dimensão moral que não pode ser esquecida. Para Sousa, que fez pesquisa na mesma região, na zona rural, "levar as crianças ao trabalho consiste no início do processo de socialização destas, pois, para seus pais, o trabalho garante a formação dos filhos enquanto cidadãos dignos, honestos e responsáveis" (2004b, p. 80)..$^{15}$ A função social do trabalho infantil na reprodução material e moral da casa sertaneja é clara: as crian- ças são "agentes imprescindíveis para o bom funcionamento da unidade familiar e, de modo mais geral, de toda a comunidade" (Pires, 2012, p. 554), na medida em que desempenham "inúmeros papéis [...] na vida familiar e comunitária" (Idem, p. 539). Quando "aprofundamos alguns dos trabalhos realizados e dos serviços prestados pelas crianças em $\mathrm{Ca}$ tingueira, compreendemos o trabalho como parte da infância, importante em um sistema de reciprocidade inter-geracional da família camponesa, mas principalmente como um mecanismo de aprendizado moral" (Idem, p. 553).

Em Catingueira é perceptível que a escolarização ficou em segundo plano nas gerações anteriores ao PBF. Se, para as avós e os avôs, a escola era praticamente inexistente, para a geração de mães e pais, embora a cidade já contasse com grupo escolar, outros motivos impediam o acesso e a continuidade dos estudos, sobretudo a necessidade de trabalhar, além da estrutura educacional precária da época. Quando havia interesse em dar continuidade aos estudos, esbarrava-se na grande dificuldade de acesso às escolas. O tempo percorrido pelas crianças para chegar ao grupo escolar girava em torno de duas horas sob o sol quente do sertão. A falta de meio de transporte na zona rural da cidade também contava negativamente. Tudo isso era motivo de fadiga, minando em grande parte a motivação para os estudos.

Em muitas situações, só mesmo um incentivo de fora do círculo doméstico nuclear faria com que os estudos pudessem ser continuados. Este foi o caso da irmã de dona Cida, hoje com 50 anos de idade, a única da família de oito irmãos que terminou o ensino superior. De acordo com dona Cida, ela foi morar na casa de um tio que lhe patrocinou os estudos. O conceito de "circulação de crianças" (Fonseca, 2002, 2007), que implica uma estratégia de cuidados infantis largamente acionada pelas classes populares no Brasil, está presente nessa dinâmica que, provavelmente, foi determinante na escolarização de muitas crianças pobres brasileiras, como a irmã de dona Cida.

Nas gerações anteriores ao PBF havia certa resistência à escolarização das meninas por parte dos pais (homens), principalmente pelos perigos morais que a educação formal poderia desencadear (Pires, 
2010a). Alguns países optam por adotar transferências diferenciadas para beneficiar a educação das meninas, como Turquia e Bangladesh. Mas não é o caso do Brasil. Atualmente, não observamos na região qualquer atitude demeritória em relação à escolarização das meninas. Pelo contrário, se podemos adiantar uma tendência em andamento, é a da priorização da escola para as meninas e do aprendizado de uma profissão tradicional para os meninos (por exemplo, agricultor e vaqueiro ${ }^{16}$ ).

No que diz respeito ao acesso a escola, observa-se uma diferença marcante entre o antes e o depois do PBF. O acesso hoje em dia é considerado fácil. Além das escolas na zona rural, o que diminiu consideravelmente as distâncias a serem percorridas, existe o incentivo direto do governo. "Estudem, porque o governo até paga para vocês estudarem!”, diz dona Cida aos filhos (apud Pires, 2011, p. 110). Seu Pedro, de 60 anos de idade, ajuda-nos a entender as mudanças em em andamento:

Hoje está muito bom. Só não estuda quem não quer. O governo dá o carro, dá a escola e até paga para os estudantes se ficarem na escola. Quando eu era criança nem escola existia. Tinha a casa da professora, mas somente quem podia pagar é que ia estudar. Hoje está muito diferente (apud Silva e Pires, 2012).

A valorização da escola, contudo, não significa desprezo ou repúdio pelo trabalho infantil. A educação está ligada ao trabalho como elemento essencial de socialização das crianças (Sousa, 2004a; Pires, 2012; Mayblin, 2010). Observamos crianças trabalhando em Catingueira, sobretudo em casa, mas isso não as impede de frequentar a escola. Aquelas que participam do Peti são completamente aliviadas das suas tarefas domésticas. Poder-se-ia supor que isso revela uma percepção dos pais sobre a permissividade do trabalho infantil. No entanto, não é isso que observamos. $\mathrm{O}$ que parece estar em jogo é o fato de que as crianças que estão no Peti são sujeitas a uma carga horária escolar considerada desgastante (dois turnos) e por isso, são liberadas das suas atividades domésticas. Isso porque entende-se que o estudo é uma atividade que demanda esforço e as crianças chegam em casa cansadas. Por outro lado, o trabalho infantil, em doses controladas e supervisionadas por adultos, é considerado recomendado. ${ }^{17}$

Como foi dito, observamos que as crianças continuam realizando pequenos serviços domésticos, sejam meninas ou meninos, mesmo que frequentem regularmente a escola. As crianças matriculadas no Peti, em larga medida, deixaram de trabalhar, uma vez que passam o dia inteiro no colégio (Pires, 2012). O Peti - é importante esclarecer - está direcionado a combater as "piores formas de trabalho infantil”. De qualquer maneira, essa questão merece uma investigação mais detida, não regrada pelo discusso universalizante de que toda forma de trabalho infantil deva ser combatida - há pesquisadores que mostram os ganhos sociais, psicológicos e políticos do trabalho das crianças (Libório e Ungar, 2010; Morrow e Vennam, 2010; Sanchéz, 2007; Nieuwenhuys, 1994; Hungerland et al., 2007, Invernizzi, 2007; Morrow, 2010). Ademais, "[n]o geral, as crianças que beneficiam-se de programas de transferência de renda condicionada raramente param de trabalhar completamente, mas trabalham menos, frequentam muito mais a escola e repetem menos de ano" (Bourdillon et al., 2011, p. 82). Não nos parece que o trabalho infantil tenha perdido seu valor na formação do homem e da mulher catingueirense, mas, diferentemente de outrora, isso não mais impede a continuidade nos estudos.

O que vimos mostrando até o momento revela mudanças geracionais importantes sendo gestadas em Catingueira em decorrência do PBF e que podem ser entendidas com base na ideia de uma "geração bolsa família". Destacamos essas mudanças no que diz respeito principalmente a: 1) expansão das possibilidades de consumo e priorização do consumo de bens voltados para as crianças (alimentos, material escolar, vestimentas e calçados); e 2) a possibilidade de permancer na escola em detrimento do trabalho na roça, tendo garantida uma renda familiar mínima. Trata-se de um fenômeno em surgimento, uma geração de crianças cujas famílias passaram a ter garantias da segurança alimentar a ponto de consumir bens considerados de luxo em um passado recente e que podem, pela primeira vez na trajetória familiar de geraçôes, priorizar a escolarização em detrimento do trabalho infantil. No 
entanto, as crianças ainda trabalham, sobretudo em casa, porque o trabalho está ligado à educação moral sertaneja (Pires, 2010a, 2010b, 2012), mas isso não parece impedir a continuidade dos estudos.

Um dos fatos observados em algumas das casas visitadas foi a presença de três gerações: avós, pais e filhos, o que favoreceu a visualização das diferenças geracionais. A geração dos avós esteve muito voltada ao trabalho na roça, quase sem contato com a escola durante a infância. Já na geração dos pais, a escola esteve presente, mas não como o primeiro compromisso das crianças. As famílias buscavam, com grande dificuldade, aliar educação e trabalho, mas esbarravam em toda sorte de dificuldade. $\mathrm{Na}$ geração atual, a educação escolar está consolidando espaço na vida das crianças, e as narrativas familiares caminham no sentido de colocá-la como prioridade na formação das crianças. Muitas entrevistadas falaram com orgulho de terem seus filhos ou netos frequentando a escola e, principalmente, de eles não precisarem parar os estudos para trabalhar.

\section{Para terminar}

Embora os resultados aqui apresentados não sejam conclusivos - e sugerem a necessidade de um esforço de pesquisa continuado, também porque o PBF tem apenas onze anos de implementação -, eles apontam mudanças na estrutura da casa sertaneja com o surgimento de uma nova geração, a "geração bolsa família", que tem como caraterísticas principais e distintivas a possibilidade de consumir alimentos, bens e serviços antes inacessíveis e a priorização da escola em detrimento do trabalho na vida da criança.

Para concluir, ressaltamos nossa preocupação com o fato de que as pesquisas têm mostrado que, embora as crianças estejam na escola, o aprendizado não tem mostrado melhoras significativas (Santos et al., 2007, p. 186). Por isso, é indiscutível a necessidade de investimentos na qualidade e na cobertura dos serviços de educação (Bradshaw e Víquez, 2008, p. 826; Soares et al., 2010, p. 186; Behrman e Parker, 2010, p. 206) para que o PBF possa romper definitivamente o ciclo intergeracional da pobreza.

\section{Notas}

1 Para um aprofundamento dessas questóes, ver Benjamin (2010), Pires (2009, 2010a, 2010b, 2013, 2014), Santos e Pires (2010), Silva Jardim (2010a, 2010b), Silva (2010, 2011), Santos (2011), Santos e Silva (2010), Silva e Pires (2012).

2 Especialmente, o trabalho de campo realizado em 2011, com a participação de seis pesquisadores, durante cinco dias, no qual foram empreendidos grupos focais com crianças, com resultados bastante reveladores (Pires, 2014), como parte das atividades do projeto de pesquisa "Do ponto de vista das crianças: o acesso, a implementação e os efeitos do Programa Bolsa Família no semi-árido nordestino" (CNPq/MDS).

3 Calculado a partir da Média de Pessoas por Domicílio 3,68 (Censo IBGE, 2010).

4 As principais condicionalidades do PBF são: $85 \%$ de frequência escolar para as crianças de 0 a 15 anos e de $75 \%$ para jovens de 16 e 17 anos e as visitas periódicas ao posto de saúde para crianças, gestantes e nutrizes.

5 Embora isso não se configure, em termos sociológicos, como uma nova classe social, ou a acessão à classe média, como gostaria o governo.

6 À epoca, não havia no município uma agência bancária, mas os saques eram efetuados dentro da lotérica em um caixa eletrônico.

7 Os nomes próprios das pessoas são fictícios.

8 Para um aprofundamento das razões e das consequências do aumento do consumo de alimentos considerados "infantis" (com alto teor de açúcar e gorduras) propiciado pelo recebimento do PBF, ver Pires (2013), que analisa como o provimento das necessidades e dos desejos alimentares das crianças contribui para o sentimento de dever cumprido materno.

9 Para um maior aprofundamento dessa questão, ver Pires (2013).

10 Para um aprofundamento dessa discussão sugiro a leitura do artigo Pires (2014), no qual desenvolvemos a ideia de que, através da condicionalidade escolar, as crianças garantem a sobrevivência material familiar. Mostramos como esse processo se dá e suas consequências para as crianças e suas famílias.

11 Para um aprofundamento do "direito das crianças" ao recebimento do benefício, ver Pires (2009, 2013, 2014).

12 A festa de São Sebastião, padroeiro da cidade, e a festa de João Pedro, comemoração junina que celebra São João e São Pedro ao mesmo tempo, interferem nas finanças das famílias de Catingueira, que fazem "planos 
e economias [o ano todo] para gastar durante a festa" (Pires, 2003, p. 89), como pudemos perceber nas entrevistas. Dona Aparecida, por exemplo, comentou o quanto a renda advinda do programa auxilia na compra de roupa nova para todos os membros da casa na época dessas festas anuais.

13 Em alguns casos, foi relatado que o dinheiro também é empregado na oferta ou no dízimo da igreja.

14 Ademais, um dos motivos para o destaque dado às dimensões educação e trabalho, em detrimento da saúde (também uma condicionalidade), surgiu durante o trabalho de campo. As famílias, quando indagadas sobre a vida antes e depois do PBF, sempre utilizavam apenas essas duas dimensôes.

15 Da mesma maneira, na sociedade brasileira existe uma concordância ou aceitação de que o ideal para crianças e adolescentes de camadas sociais menos favorecidas seria aprender desde cedo um ofício, evitando a marginalidade, contribuindo para a renda familiar e preparando a criança para o mercado de trabalho competitivo. "O trabalho de crianças e jovens é visto como 'formador', facilitando o início da vida profissional" (Dauster, 1992, p. 33).

16 A escolarização, embora implique prestígio, não parece ser entendida como o caminho mais promissor para garantir a sobrevivência financeira das famílias. Talvez, por isso, a evasão escolar entre os meninos seja tolerada com mais facilidade, uma vez que, sobre eles, pesará no futuro o fardo de sustentar a família.

17 A ideia do trabalho das crianças como forma de socialização moral foi desenvolvida em outra oportunidade (Pires, 2012).

\section{BIBLIOGRAFIA}

ADATO, M. (2008), "Combining survey and ethnography methods to improve evaluation of condicional cash transfer programs". International Journal of Multiple Research Approaches, 2: 222-236.

ADATO, M.; ROOPNARAINE, T. \& BECKER, E. (2011), "Understanding use of health services in conditional cash transfer programs: insights from qualitative research in latin America and Turkey". Social Science \& Medicine, 72: 1921-1929.

BATESON, G. (2000), Steps to an ecology of mind. Londres, Paladin.
BEHRMAN, J. R. \& PARKER, S. W. (2010), "Impacts of conditional cash transfer progra$\mathrm{ms}$ in education", in Adato M. E Hoddinott J. (orgs.), Conditional cash transfers in Latin America, Baltimore, The John Hopkins University Press/ International Food Policy Research Institute, pp. 191-211.

BENJAMIN, T. (2010), "Brebotos e burugangas: analisando o 'empoderamento' infanto-juvenil no sertão paraibano”. CAOS - Revista Eletrônica de Ciências Sociais, 15: 31- 36.

BOURDIEU, Pierre. ([1970] 1999), "A Casa Kabyle ou o mundo às avessas". Cadernos de Campo, 8 (9): 147-159.

BOURDILLON, Michael; LEVISON, Deborah; MYERS, William \& WHITE, Ben. (2011), Rights and wrongs of children's work: new perspectives from research and action. New Brunswisk/ New Jersey/Londres, Rutgers University Press.

BRADSHAW, S. \& VÍQUEZ A. Q. (2008), "Women beneficiaries or women bearing the cost? A genderend analysis of the red de protección social in Nicaragua". Development and Change, 39 (5): 823-844.

CECCHINI, Simone \& MADARIAGA, Aldo. (2011), Conditional cash transfer programmes: the recent experience in Latin America and the Caribbean. Nova York, Eclac/Sida.

COHN, Amélia. (2012), Cartas ao presidente Lula: Bolsa Família e direitos sociais. Rio de Janeiro, Azougue.

DAUSTER, T. (1992), "Uma infância de curta duração: trabalho e escola". Cadernos de Pesquisa, 82: 31-36.

DEBERT, G. G. (1994), "Pressupostos da reflexão antropológica sobre a velhice”, in G. G. Debert (org.), Antropologia e velhice. Campinas, IFCH/ Unicamp, pp. 7-30 (Textos Didáticos, 13).

DE BRITTO, T. F. (2008), "The emergence and popularity of conditional cash transfers in Latin America", in Armando Barrientos e David Hulme (orgs.), Social protection for the poor and the poorest: concepts, policies and Politics, Hampshire, Palgrave Macmillan, pp. 181-193.

DINIZ, S. (2007), "Critérios de justiça e programas de renda mínima”. Revista Katálysis, 10 (1): 105-114. 
DOMINGUES, José M. (2002), "Gerações, modernidade e subjetividade". Tempo Social, 14 (1): 67-89.

DUARTE, Gisléia Benini; SAMPAIO, Breno \& SAMPAIO, Yony. (2009), "Programa Bolsa Família: impacto das transferências sobre os gastos com alimentos em famílias rurais". Rev. Econ. Sociol. Rural [online], 47(4): 903-918.

ESCOREL, Sarah. (2014), Resenha ao livro Cartas ao Presidente Lula, de Amélia Cohn. Ciênc. Saúde Coletiva [online], 19 (2): 651652. Disponível em http://www.scielo.br/ scielo.php?script $=$ sci_arttext $\&$ pid $=$ S1413$-81232014000200651 \& \operatorname{lng}=$ en \&nrm=iso.

FARRINGTON, J. \& SLATER, R. (2006), “Introduction: cash transfer: panacea for poverty reduction or money dow the drain?". Development Policy Review, 24 (5):499-511.

FISZBEIN, A. \& SCHADY, N. (2009), Conditional cash transfers reducing present and future poverty. Washington, D.C., World Bank Policy Research Report.

FONSECA, C. (2002), "Mãe é uma só? Reflexão sobre alguns casos brasileiros". Psicol., 13 (2): 49-68.

(2007), "De família, reprodução e parentesco: algumas considerações". Cadernos Pagu, 29: 9-35.

HALL, A. (2006), "From Fome Zero to Bolsa Família: social policies and poverty alleviation under Lula”. Journal of Latin American Studies, 38 (4): 689-709.

HANLON, J.; Barrientos, A. \& Hulme, D. (2010), Just give money to the poor: the development revolution from the Global South. Sterling, Kumarian Press.

HUNGERLAND, B.; LIEBEL, M.; MILNE, B. \& WIHSTUTZ, A. (2007), Working to be someone: child focused research and practice with working children. Londres/Philadelphia, Jessica Kingsley Publishers.

INVERNIZZI, A. (2007), "Children's work as 'participation': thoughts on ethnographic data in Lima and Algarve", in Beatrice Hungerland, Manfred Liebel, Brian Milne e Anne Wihstutz, Working to be someone: child focused research and practice with working children.
Londres/Philadelphia, Jessica Kingsley Publishers, pp. 135-144.

LAVINAS, Lena. (2006), "From means-test schemes to basic income in Brazil: exceptionality and paradox". International Social Security Review, 59 (3): 103-125.

LAVINAS, Lena \& BARBOSA, Maria Ligia de Oliveira. (2000), "Combater a pobreza estimulando a freqüência escolar: o estudo de caso do Programa Bolsa-Escola do Recife”. Dados, 43 (3): 447-477.

LIBÓRIO, R. M. C. \& UNGAR, M. (2010), "Children's perspectives on their economic activity as a pathway to resilience". Children \& Society, 24 (4): 326-338.

LIGNANI, J. de B.; SICHIERI, R.; BURLANDY, L. \& SALLES-COSTA, R. (2011), "Changes in food consumption among the Programa Bolsa Família participant families in Brazil”. Public Health Nutrition, 14 (5): 785-792.

LOMELI, E. V. (2008), "Conditional cash transfers as social policy in Latin America: an assessment of their contributions and limitations". Annual Review of Sociology, 34: 475-99.

LUND, Francie; NOBLE, Michael; BARNES, Helen \& WRIGHT, Helen. (2009), "Is there a rationale for conditional cash transfers for children is South Africa?". Transformations - Critical Perspectives on Southern Africa, 70: 70-91.

MAYBLIN, M. (2010), Gender, catholicism and morality in Brazil: virtuous husbands, powerful wives. Nova York, Palgrave/Macmillan.

MOLYNEUX, M. (2006), "Mothers at the service of the new poverty agenda: Mexico's condicional transfer programme". Social Policy \& $A d-$ ministration, 40 (4): 425-449.

MONNERAT, G. L.; SENNA, M. de C. M.; SCHOTTZ, V.; MAGALHĀES, R. \& BURLANDY, L. (2007), "Do direito incondicional à condicionalidade do direito: as contrapartidas do programa Bolsa Família”. Ciência \& Saúde Coletiva, 12 (6): 1453-1462.

MORROW, V. (2010), "Should the world be really free of "child labour"? Some reflections". Childhood, 17 (4): 435-440.

MORROW, V. \& VENNAM, U. (2010), “Combining work and school: the dynamics of girl's 
involvement in agricultural work in Andhra Pradesh, India”. Children \& Society, 24 (4): 303-314.

MORTON, Gregory Duff. (2013), "Acesso à permanência: diferenças econômicas e práticas de gênero em domicílios que recebem Bolsa Família no sertão baiano". Revista Politica e Trabalho, 38: 43-46.

NIEUWENHUYS, O. (1994), Children's lifeworlds: gender, welfare and labour in the development world. Londres, Routledge.

PIRES, Flávia. F. (2003), "Os filhos-ausentes e as penosas de São Sebastiãozinho: etnografia da Festa da Catingueira-PB. Rio de Janeiro, dissertação de mestrado, UFRJ, Museu Nacional. . (2009), "A casa sertaneja e o Programa Bolsa-Família: questôes para pesquisa”. Política \& Trabalho, 27: 1-12.

(2010A), "O Programa Bolsa Família e o consumo das meninas e dos meninos no semiárido nordestino". Texto apresentado no IX Seminário Internacional Fazendo Gênero, Florianópolis.

(2010B), "Geração Bolsa Família: as crianças, suas famílias e os impactos sociais de uma política pública no semiárido nordestino brasileiro". Trabalho apresentado no $34^{\circ}$ Encontro Anual da Anpocs, Caxambu-MG.

(2012), "Crescendo em catingueira: criança, família e organização social no semiárido nordestino". Mana, 18: 539-561.

(2013), "Comida de criança e o Programa Bolsa Família: moralidade materna e consumo alimentar no semiárido". Política \& Trabalho, 38: 123-135.

(2014), "Child as family sponsor: an unforeseen effect of Programa Bolsa Familia in northeastern Brazil". Childhood, 21: 134-147.

QUIJANO, M. A. F. (2009), "Social policy for poor rural people in Colombia: reinforcing tradicional gender roles and identities?". Social Policy \& Admistration, 43 (4): 397-408.

REGO, W. L. (2008), “Aspectos teóricos das políticas de cidadania: uma aproximação ao Bolsa Família”. Lua Nova, 73: 147-185.

REGO, W. L. \& PINZANI, A. (2013), "Vozes do Bolsa Família: autonomia, dinheiro e cidadania”. São Paulo, Editora da Unesp.
RESENDE, A. Costa \& OLIVEIRA, A. Camilo de (2008), "Avaliando resultados de um programa de transferência de renda: o impacto do Bolsa-Escola sobre os gastos das famílias brasileiras". Estudos Econômicos, 38 (2): 235-265.

SÁNCHEZ, M. A. R. (2007), “'Helping at home': the concept of childhood and work among the Nahuas of Tlaxcala, Mexico", in Beatrice Hungerland, Manfred Liebel, Brian Milne e Anne Wihstutz, Working to be someone: child focused research and practice with working children. Londres/Philadelphia, Jessica Kingsley Publishers, pp. 87-95

SANTOS, L. M. P. et al. (2007), "Perfil nutricional de criancas menores de cinco anos do semiárido brasileiro", in J. Vaitsman e R. Paes-Souza (orgs.), Avaliação de políticas de programas do MDS: resultados, Brasília, Sagi/MDS.

SANTOS, P. O. S. (2011), "Deixa eu Falar! Uma análise antropológica do Programa Bolsa Família a partir das crianças beneficiadas do alto sertão paraibano". Monografia de fim de curso de Ciências Sociais da Universidade Federal da Paraíba (UFPB).

SANTOS, P. O. S. \& PIRES, F. F. (2010), "Nós somos combinados: negociando o destino do benefício do Programa Bolsa Família no município de Catingueira-PB”. Trabalho apresentado no XVIII Encontro de Iniciação Científica, João Pessoa.

SANTOS, P. O. S. \& SILVA, J. K. O. (2010), "Elas decidem? Analisando o papel familiar da mulher a partir do Programa Bolsa Família”. Trabalho apresentado na 27a Reunião Brasileira de Antropologia, Belém.

SILVA, Antonio Luiz da \& PIRES, Flávia Ferreira. (2012), "A criança e o ECA na pequena catingueira paraibana: direitos reivindicados, direitos conquistados?". São Paulo. Anais da RBA.

SILVA, J. K. R. (2010), "Eu compro tudo de pelota": o consumo das crianças e o Programa Bolsa Família. Trabalho apresentado no IX Centro de Ciências Humanas, Letras e Artes (CCHLA), João Pessoa.

SILVA, J. K. R. (2011), "Eu compro tudo de pelota”: o Programa Bolsa Família e a expansão do consumo infantil em Catingueira-PB”. Mono- 
grafia de fim de curso de graduação em Ciências Sociais, UFPB.

SILVA, M. O. S. (2007), “O Bolsa Família: problematizando questões centrais na política de transferência de renda no Brasil”. Ciênc. Saúde Coletiva [online], 12 (6): 1429-1439.

SILVA JARDIM, G. A. da. (2010a), "Reflexões antropológicas a partir de uma política pública para crianças". CAOS - Revista Eletrônica de Ciências Sociais, 15: 37-45.

SILVA JARDIM, G. A. da. (2010b), "A casa sertaneja entre geraçôes: os impactos do Programa Bolsa Família na cidade de Catingueira-PB”. Monografia de fim de curso de graduação em Ciências Sociais, UFPB.

SOARES, F. V.; RIBAS, R. P. \& OSÓRIO, R. G. (2007), "Avaliando o impacto do Programa Bolsa Família: uma comparação com programas de transferência condicionada de renda de outros países". Centro Internacional da Pobreza, Ipea/PNUD.

(2010), "Evaluating the impact of Brazil's Bolsa Família”. Latin American Research Review, 45 (2): 173-190.

SOARES, S. S. (2006), "Distribuição de renda no Brasil de 1976 a 2004, com ênfase no período entre 2001 a 2004”. Texto para discussão, 1166. Brasília, Instituto de Pesquisas Econômicas Aplicadas (Ipea).

SOUZA, E. do N. (2011), "As crianças e o Programa Bolsa Família em Catingueira $(\mathrm{Pb})$ : uma reflexão antropológica da condicionalidade escolar a partir do ponto de vista das crianças". Monografia de fim de curso de ciências sociais, UFPB.

SOUSA, E. L. de. (2004a), "Que trabalhais como se brincásseis": trabalho e ludicidade na infância Capuxu". Campina Grande, dissertação de mestrado em ciências sociais, Universidade Federal de Campina Grande, Paraíba. (2004B), "Relativizando o trabalho infantil a partir de uma experiência etnográfica: o caso das crianças Capuxu". Caderno Pós Ciências Sociais, 1 (2): 75-94.

SUPLICY, Eduardo Matarazzo. (2006), Renda básica de cidadania: a resposta dada pelo vento. Porto Alegre, L\&PM Pocket.
(2007), "O direito de participar da riqueza da nação: do Programa Bolsa Família à Renda Básica de Cidadania”. Ciênc. Saúde Coletiva [online], 12 (6): 1623-1628.

WEISSHEIMER, M. A. (2006), Bolsa Família: avanços, limites e possibilidades do programa que está transformando a vida de milhões de famílias no Brasil. São Paulo, Editora Fundação Perseu Abramo.

ZIMMERMANN, C. R. (2006), "Social programs from a human rights perspective: the case of the Lula admnistration's Family Grant in Brazil". Sur, International Journal on Human Rights, 3 (4): 145-161.

\section{Relatórios}

CEDEPLAR. (2007), Sumário executivo: avaliação de impacto do Programa Bolsa Família. Centro de Desenvolvimento e Planejamento Regional/ UFMG. Ministério do Desenvolvimento Social e Combate à Fome, Brasília, Sagi.

MDS. (2011), "Histórico das repercussões por descumprimento de condicionalidades". Disponível em http://www.mds.gov.br/programabolsafamilia/condicionalidades/historico-das-repercussoes-por-descumprimento-de-condicionalidades.

SUÁREZ ET AL. (2006), “O Programa Bolsa Família e o enfrentamento das desigualdades de gênero: o desafio de promover o reordenamento do espaço doméstico e o acesso das mulheres ao espaço público". Relatório compreensivo de pesquisa apresentado ao Ministério do Desenvolvimento Social e Combate à Fome (mds) e ao Department for International Development (dfid). 


\section{GERAÇÃO BOLSA FAMÍLIA: ESCOLARIZAÇÃO, TRABALHO INFANTIL E CONSUMO NA CASA SERTANEJA (CATINGUEIRA/PB)}

Flávia Ferreira Pires e

George Ardilles da Silva Jardim

Palavras-chave: Programa Bolsa Família; Geração; Escolarização; Trabalho Infantil; Consumo.

Este artigo analisa os efeitos do Programa Bolsa Família (PBF) na cidade de Catingueira, Paraíba, no que diz respeito às transformaçōes ocorridas no seio das famílias que passaram a receber o benefício. Observamos uma mudança geracional em andamento, que pode ser entendida a partir do conceito de "geração bolsa família", em que pesam narrativas familiares sobre consumo, escolarização e trabalho infantil. A pesquisa de campo foi realizada por cinco pesquisadores, utilizando-se, como técnicas, a observação participante e entrevistas com mães beneficiárias.

\section{THE BOLSA FAMÍLIA GENERATION: EDUCATIONAL ATTAINMENT, CHILD LABOR AND CONSUMPTION IN THE BACKCOUNTRY HOME (CATINGUEIRA/PB)}

Flávia Ferreira Pires and George Ardilles da Silva Jardim

Keywords: The Bolsa Familia Program; Generation; Child Labor; Consumption.

This article analyzes the effects of the Bolsa Familia Program in the town of Catingueira, Paraíba, Brazil, in relation to the changes within families that have started receiving the benefit. It was observed as being under way a generational change, which can be understood under the concept of 'the bolsa familia generation' and perceived through family narratives concerning trajectories associated with consumption, children's attendance to schools, and child labor. The research in the field was held with the participation of five researchers, using as research techniques participant observation and interviews with the beneficiary mothers.
GÉNÉRATION BOLSA FAMÍLIA: SCOLARISATION, TRAVAIL DES ENFANTS ET CONSOMMATION DANS LE FOYER SERTANEJO (CATINGUEIRA/PB)

Flávia Ferreira Pires et George Ardilles da Silva Jardim

Mots-clés: Programme Bolsa Família; Génération; Scolarisation; Travail des Enfants; Consommation.

Cet article analyse les effets du Programme Bolsa Familia (Bourse familiale) dans le village de Catingueira, dans l'état de la Paraíba, au Brési. Il compare ces effets face aux changements qui ont eu lieu au sein des familles qui ont reçu ce bénéfice social. Nous avons détecté un changement de génération en cours, qui peut être compris à partir du concept de "génération Bolsa Família ", qui concerne les trajectoires associées à la consommation, la scolarisation et le travail des enfants. Le recherche sur place a été entreprise par cinq chercheurs qui ont employé des techniques d observation participative et des entretiens avec les mères bénéficiaires de ce programme social. 